\title{
ARTIGO
}

\section{Desigualdades de gênero e trabalho após a aposentadoria}

\author{
Gender inequalities and work after retirement
}

\begin{abstract}
Maria Engrácia de Carvalho Chaves, D.Sc.
FUNDACENTRO/UDBA, Doutora em Saúde Pública. E-mail: maria.chaves@fundacentro.gov.br
\end{abstract}

Estela M. L. Aquino, D.Sc.

Instituto de Saúde Coletiva, Universidade Federal da Bahia, Doutora em Saúde Pública.

\begin{abstract}
RESUMO: O trabalho após a aposentadoria é tema de interesse na literatura científica, com destaque dos benefícios da atividade laboral sobre a saúde e o bem-estar de aposentados. Neste estudo, pretendemos agregar alguns elementos que devem ser levados em consideração nessa discussão, com o objetivo de trazer à tona o debate sobre trabalho após a aposentadoria, ressaltando os efeitos das desigualdades de gênero sobre a reinserção no mercado de trabalho. Essas desigualdades estão presentes durante todo o curso de vida, manifestando-se, de modo particular, no mundo do trabalho. A trajetória no trabalho distingue-se claramente para os homens e para as mulheres. Com frequência, as mulheres se inserem em empregos parciais e interrompem suas atividades no mercado de trabalho, dividindo-se entre a vida doméstica e a vida laboral, o que interfere na construção de sua carreira. Com o envelhecimento, as desigualdades de gênero no trabalho se manifestam mais acirradas, com repercussão no tipo de aposentadoria e na reinserção no mercado de trabalho, sendo geralmente mais precária entre as mulheres. Este ensaio pretende chamar a atenção para a necessidade de proteção para grupos de trabalhadores e de trabalhadoras que envelhecem e querem ou precisam voltar a trabalhar, visando ao bem-estar e à saúde dessa população.
\end{abstract}

Palavras-chave: trajetória laboral e aposentadoria, gênero e mercado de trabalho tardio, precarização do trabalho na velhice. 


\begin{abstract}
Work after retirement is a topic of interest in the scientific literature, with an emphasis on the benefits of work activity on retirees' health and wellbeing. In this study, we aim to bring together some elements that must be taken into consideration in this discussion, with the objective of raising the debate about work after retirement, highlighting the effects of gender inequalities on labor market reentry. These inequalities are present during the entire life course, manifesting particularly in work life. Employment trajectories are clearly different for men and women. Often, women take on part-time jobs and interrupt their activities on the labor market, dividing themselves between domestic life and work life, which interferes with the construction of their careers. With aging, gender inequalities in work manifest in deeper ways, with repercussions in the type of retirement and reentry in the labor market, with these being generally more precarious among women. This essay seeks to call attention to the need for protection for groups of aging workers who want or need to return to work, aiming to promote the wellbeing and health of this population.
\end{abstract}

Keywords: employment trajectory and retirement, gender and late labor market, precarization of work in old age.

\title{
1. INTRODUÇÃO
}

O significado da palavra aposentadoria relaciona-se com a retirada do mundo exterior e refúgio nos aposentos da casa. Para se pensar a aposentadoria, há que se considerar o contexto demográfico, histórico, sociocultural, econômico e político no qual os/as trabalhadores/as estão inseridos/as. A forma de se aposentar guarda relação com as condições de trabalho vividas, no que diz respeito aos aspectos positivos como reconhecimento, status social, boa remuneração, sensação de utilidade e de pertencimento, e com os aspectos negativos, destacando-se a remuneração insuficiente, que funciona como impedimento para a realização dos planos. Assim, as desigualdades às quais os/as trabalhadores/as estão expostos no mundo do trabalho terão repercussões na aposentadoria, incluindo-se as de gênero e raça/cor (FERNANDES; ZORDAN, 2012).

Estudos de revisão da literatura brasileira sobre aposentadoria, incluindo-se o trabalho nessa fase da vida, referiram os seguintes fatores relacionados à decisão de continuar trabalhando: auto avaliação positiva da saúde, menor idade, flexibilidade de horário e controle do próprio trabalho (FRANÇA et al., 2013); aumento da renda;

Laborare. Ano IV, Número 6, Jan-Jun/2021, pp. 152-171. ISSN 2595-847X. https://revistalaborare.org/ DOI: https://doi.org/10.33637/2595-847x.2021-70 
necessidade de sentir-se produtivo; convívio social; desejo de se atualizar, ressaltando-se o papel constitutivo do trabalho na identidade do sujeito (BOEHS et al., 2017). No estudo realizado por Ribeiro et al. (2015), os autores relataram que os aposentados consideraram o trabalho, por um lado, como lazer, necessidade de aumentar a renda, o poder de decisão no domicílio e a autoestima, possibilidade de realizar um trabalho desejado, conforto físico, emocional e social; por outro lado, o trabalho após a aposentadoria foi percebido como perda, com vínculos empregatícios mais frágeis, menos qualificado e remuneração inferior, caracterizando uma situação de precariedade.

Nessas revisões na área de Psicologia, não foi observada uma abordagem de gênero que apontasse para desigualdades entre os homens e as mulheres no que se refere à escolha ou à necessidade de continuar trabalhando após a aposentadoria.

Por outro lado, ainda no Brasil, vários aspectos das desigualdades de gênero na velhice vêm sendo estudados por algumas autoras, incluindo-se a maior precarização do trabalho para as idosas (DEBERT, 1994; KRELING, 2001; BRITTO da MOTTA, 1999; CAMARANO, 2004).

Uma abordagem na perspectiva de gênero pode ajudar a compreender os processos que ocorrem na velhice e contribuir para desvelar desigualdades anteriores durante o percurso da vida e as conexões entre gênero e tipo de aposentadoria a ser usufruída (FARRÉ, 1996; FINCH, 2014). Estudos demonstram que as mulheres recebem uma pensão menor do que os homens, geralmente precisam complementar renda e têm maior dificuldade para se reinserir no mercado de trabalho após a aposentadoria (FINCH, 2014; Di GESSA et al., 2017).

Importante ressaltar que as mulheres que se encontram hoje aposentadas pertencem a uma geração com menor participação na força de trabalho formal, que vem se modificando gradativamente a partir dos anos 80 , quando trabalhos eventuais para complementação da renda familiar se tornam regulares.

A dupla ou tripla jornada que caracteriza o trabalho da maioria das mulheres, em nossas sociedades, agrava-se com o envelhecimento, não apenas pelas limitações próprias desse período, quanto pela necessidade de cuidar de familiares portadores de graus variados de incapacidade, o que determina a aposentadoria precoce e dificulta a reinserção no mercado de trabalho (CICARELLI; VAN SOEST, 2018; STOIKO; STROUGH, 2018).

Laborare. Ano IV, Número 6, Jan-Jun/2021, pp. 152-171. ISSN 2595-847X. https://revistalaborare.org/ DOl: https://doi.org/10.33637/2595-847x.2021-70 
Fatores culturais e políticos estão diretamente relacionados à inserção de mulheres de meia idade no mercado de trabalho. Em países em que os serviços de cuidado oferecidos pelo Estado são limitados ou naquelas culturas em que se pressupõem obrigações em relação às gerações pregressas, as mulheres cuidadoras de familiares têm maior dificuldade para manter seus níveis de emprego (NALDINI; PAVOLINI; SOTERA, 2016).

Adiciona-se às desigualdades de gênero observadas na velhice a política de aumento do tempo de trabalho em países desenvolvidos, com implicações no fenômeno crescentemente estudado da precarização dos vínculos e das condições de trabalho, que toma forma especial nesse grupo populacional. Para implementação dessa política, os interesses econômicos ganham prioridade em detrimento da responsabilidade em preservar a saúde de idosos e idosas. Autores que se utilizam da análise de gênero têm chamado a atenção para as desvantagens das mulheres, que acabam se inserindo em trabalhos mais precários, que têm interseções com o já citado trabalho não remunerado de cuidados a familiar e a trajetória de empregos muitas vezes interrompida ou prejudicada pelo desempenho do seu papel socialmente atribuído (FELIX, 2016; KREKULA; VICKERSTAFF, 2017; Ni LEIME; LORETTO; STREET, 2017; STREET, Ni LEIME, 2017; LAIN et al., 2019).

Felix (2016) refere que no Brasil repetiu-se o erro dos países ditos desenvolvidos, ao discutir-se o aumento do tempo de trabalho antes da aposentadoria e não se levar em consideração a questão da empregabilidade dos trabalhadores acima dos 60 anos. Segundo o autor, na atuação do Estado no campo da previdência social, houve uma dissonância entre o discurso oficial sobre a prorrogação da aposentadoria e a realidade do mercado de trabalho que, quando absorve os idosos e idosas, o faz em empregos precários. As mulheres são, mais uma vez, as que mais sofrem com essa realidade.

Outra questão importante na vida de trabalhadores idosos refere-se à situação de saúde, que demanda uma abordagem das suas relações com o trabalho na velhice, após a aposentadoria. Essas relações tanto podem ser positivas quanto negativas (STAUDINGER et al., 2016).

A discussão sobre trabalho é ampla e neste texto serão enfatizados aspectos relativos à importância do trabalho como fonte de ganhos simbólicos. Os ganhos objetivos, especialmente ligados à sobrevivência, serão discutidos ao longo do texto, na perspectiva das questões ligadas a gênero. A escolha de trabalhar - ou não - após a

Laborare. Ano IV, Número 6, Jan-Jun/2021, pp. 152-171. ISSN 2595-847X. https://revistalaborare.org/ DOl: https://doi.org/10.33637/2595-847x.2021-70 
aposentadoria também será considerada na perspectiva dos efeitos do trabalho sobre a saúde psíquica, ainda que de forma breve.

O trabalho é estruturante para a saúde mental, tanto nos aspectos positivos, quanto pela possibilidade de gerar sofrimento ou adoecimento. Assim, é um espaço dialético de prazer/saúde e sofrimento/adoecimento, possibilitando uma pendulação entre esses dois polos. As relações entre o trabalho, o prazer, a saúde, o sofrimento e o adoecimento são complexas. O processo de sublimação e criatividade, assim como os fatores de proteção à saúde psíquica, como solidariedade, ética, construção positiva da identidade no trabalho e o reconhecimento dos pares podem ser propiciados pela inserção no trabalho. Entretanto, se não houver a possibilidade de pendulação entre esses dois polos, devido a estruturas hierárquicas rígidas e inflexíveis no trabalho, o sofrimento pode persistir e redundar em adoecimento (DEJOURS, 1994).

O que Dejours (1994) nos diz é que o trabalho é um locus fundamental para a construção da identidade do indivíduo, seja por uma via construtiva, em que o trabalho possibilita agregar elementos que sustentam uma boa autoestima, seja representando algo sem valor nem utilidade. Quando se dá a identificação com esse "lugar" de desvalido e inútil, o trabalho pode se tornar fonte de sofrimento, que, se agravado e não redirecionado para o polo da saúde, pode causar adoecimento, seja psíquico ou físico. Nesse sentido, é fundamental o olhar do outro. O reconhecimento que advém dos pares no ambiente de trabalho constitui-se um dos pilares imprescindíveis para a construção de uma identidade positiva no trabalho. Esses mesmos elementos subjetivos estarão presentes no trabalho após a aposentadoria.

Em estudos qualitativos nacionais, o trabalho é referido, pelos/as aposentados/as, como relevante para o desenvolvimento da identidade e de laços sociais (BITENCOURT et al., 2011). Da mesma forma, a necessidade de sentir-se produtivo, de realização pessoal, de interação e atualização é fator preponderante na decisão de continuar trabalhando, assim como a complementação de renda (ANTUNES; MORÉ, 2014).

Sendo assim, devem-se marcar as possibilidades de repercussão do trabalho na saúde psíquica. Uma repercussão benéfica é aquela em que os ganhos obtidos através do trabalho também representam ganhos simbólicos, de reconhecimento, sentimento de pertencimento a um grupo, de utilidade, enfim, de valor, o que impacta positivamente o psiquismo e favorece maior bem-estar e satisfação na vida. Por outro lado, quando o trabalho é penoso, sofrido, em que ocorre desgaste físico e mental, o esperado é que ele repercuta negativamente sobre o bem-estar e, consequentemente, sobre a saúde, representando, essencialmente, apenas a obrigatoriedade de adquirir os meios de sobrevivência.

Laborare. Ano IV, Número 6, Jan-Jun/2021, pp. 152-171. ISSN 2595-847X. https://revistalaborare.org/ DOl: https://doi.org/10.33637/2595-847x.2021-70 
Seguindo o raciocínio acima, que trabalhador ou trabalhadora gostaria de continuar trabalhando após a aposentadoria? Aquele/a que tem prazer na realização do seu trabalho e que, para além da remuneração, alcança ganhos simbólicos, ou o que trabalha apenas para obter rendimentos que lhe possibilitem a sobrevivência, desgastando-se cada vez mais, vivenciando uma situação de grande precariedade e prejudicando a sua saúde?

Assim, este texto, organizado na forma de um ensaio, busca discutir os aspectos mencionados e contribuir para reforçar a posição de que, tanto o prolongamento do tempo de trabalho antes da aposentadoria, quanto o trabalho após a aposentadoria, não podem ser prescritos como se trouxessem benefícios homogêneos a todos; ao contrário, especificidades de gênero e do tipo de trabalho desenvolvido devem ser norteadores de medidas de proteção específicas, especialmente para as mulheres idosas. Nesse sentido, nosso objetivo é trazer à tona o debate sobre trabalho após a aposentadoria, ressaltando os efeitos das desigualdades de gênero sobre a reinserção e a precarização no mercado de trabalho, na velhice.

\section{MULHERES E HOMENS NO TRABALHO: UMA ESFERA MARCADA POR GÊNERO}

Durante muito tempo, as diferenças na inserção laboral de mulheres e homens foram naturalizadas. O próprio conceito de trabalho, no paradigma dominante, como aquele realizado na produção, excluía outras formas de atividades laborais, como atividades domésticas e outras de cuidados aos doentes, às crianças e aos velhos, além de atividades informais, como a agricultura de subsistência, o artesanato e o comércio informal de mercadorias (De MELO; THOMÉ, 2018). Os estudos sobre a relação entre trabalho e saúde voltavam-se ao trabalho industrial, onde as mulheres estavam pouco representadas e o conhecimento produzido era baseado quase exclusivamente na observação de populações compostas por homens (DUMAIS, 1992).

A partir da década de 1970, uma crescente crítica ao androcentrismo da ciência (GERGEN, 1993; SCHIEBINGER, 2001), à ausência das mulheres nos estudos empíricos e à inadequação dos modelos teóricos somou-se à crise de paradigmas que se avolumava desde a década anterior, e, na sociologia do trabalho, as pesquisas iniciais, que apenas acrescentavam as mulheres, utilizando as mesmas categorias de análise empregadas tradicionalmente, foram sendo substituídas por outras que questionavam os próprios modelos existentes, como inadequados à apreensão do trabalho feminino, desembocando, na década de 1990, nos estudos de gênero (NASH, 1985; CASTRO; LAVINAS, 1992; SCARBOROUGH e RISMAN, 2020).

Laborare. Ano IV, Número 6, Jan-Jun/2021, pp. 152-171. ISSN 2595-847X. https://revistalaborare.org/ DOl: https://doi.org/10.33637/2595-847x.2021-70 
Gênero como categoria analítica foi conceituado por Joan Scott (1995:86) como "um elemento constitutivo de relações sociais baseado nas diferenças percebidas entre os sexos (...) é uma forma primeira de significar as relações de poder". Segundo Wharton (2009), é um dos princípios de organização social e, como tal, embasa a distribuição de poder e recursos na vida social, incluindo a esfera do trabalho.

As atribuições de papéis de gênero começam antes mesmo do nascimento, quando se constroem expectativas de comportamento e personalidade, definem-se cores de roupas e adereços, brinquedos e nomes apropriados a meninas e meninos (WHARTON, 2009). E isso é apenas o começo já que as diferenças conformam desigualdades que se instituem precocemente e vão reproduzir-se ao longo do curso de vida de homens e mulheres. Atributos de força, coragem e bravura para eles, e de paciência, meiguice e cuidado para elas, conformam trajetórias que influenciam mais tarde a inserção no mercado de trabalho, fenômeno que se expressa na noção de divisão sexual do trabalho.

Para Kergoat (1987), é uma mesma divisão sexual e social do trabalho, decorrente de relações sociais de sexo, que, na esfera da produção, traduz-se em ocupações "femininas" e "masculinas" e, na família, perpetua o trabalho doméstico e o cuidado dos filhos como atividades próprias e exclusivas das mulheres. Tradicionalmente, são elas que ocupam posições mais baixas na hierarquia de comando, recebem salários mais baixos e são relegadas às atividades de tempo parcial e precarizadas.

Alguns dados do Instituto Brasileiro de Geografia e Estatística (IBGE) de 2016 explicitam essas desigualdades. Naquele ano, embora o percentual das mulheres com escolaridade superior fosse maior que o dos homens $(23,5 \%$ das mulheres brancas e $10,4 \%$ das mulheres pretas e pardas, em contraposição a $20,7 \%$ dos homens brancos e $7 \%$ dos homens pretos e pardos), as mulheres recebiam uma média de 1764 reais, enquanto os homens tinham uma média de renda igual a 2306 reais, com uma razão de rendimentos igual a 76,5\%. A proporção de ocupados no trabalho em tempo parcial, por sexo e raça, era de $11,9 \%$ para homens brancos e $25 \%$ para mulheres brancas, enquanto para os homens negros e as mulheres negras, essas proporções foram de $16 \%$ e $31,3 \%$, respectivamente, indicando maior nível de precarização do trabalho entre essas últimas.

Os cargos gerenciais eram ocupados por $60,9 \%$ de homens e $39,1 \%$ de mulheres. Percebe-se que, quando a idade aumenta, diminui a proporção de mulheres nesses cargos, começando com 43,1\% na faixa etária de 16 a 29 anos, com queda significativa para a faixa de 60 anos ou mais, com $31,8 \%$. Nos cargos políticos, $10,5 \%$ dos assentos na Câmara dos Deputados eram ocupados por mulheres - em

Laborare. Ano IV, Número 6, Jan-Jun/2021, pp. 152-171. ISSN 2595-847X. https://revistalaborare.org/ DOl: https://doi.org/10.33637/2595-847x.2021-70 
contraposição a 23,6\% em todo o mundo -, assim como $16 \%$ dos assentos do Senado ${ }^{1}$.

Retomando a questão da divisão sexual do trabalho (KERGOAT, 1987), a crescente participação feminina no mercado de trabalho, que decorreu do aumento da escolarização e das mudanças no valor do trabalho para as mulheres, não as tem desobrigado das antigas funções de cuidado da casa, dos filhos, doentes e idosos. Como resultado, as mulheres têm uma carga horária superior à dos homens e geralmente "o tempo do assalariamento é condicionado pelo tempo do trabalho doméstico" (HIRATA, 2003:67), equação relevante na determinação do conflito trabalho/família, que tem grandes impactos sobre a vida e a saúde das trabalhadoras.

Como exemplo, o estudo do IBGE (2016), a partir de dados da Pesquisa Nacional por Amostra de Domicílios Contínua, sobre a média de horas dedicadas aos cuidados de pessoas e/ou afazeres domésticos por mulheres e homens, mostrou que as mulheres dedicavam 18,1 horas semanais, enquanto os homens se ocupavam 10,5 horas, considerando todas as faixas etárias.

A partir da idade madura, o conflito trabalho/família geralmente se apresenta em novos formatos em que o cuidado dos filhos e do marido é substituído pelo de pais e de outros parentes. Assim, as mulheres retiram-se mais cedo do mercado de trabalho e/ou têm mais dificuldade para reinserir-se após a aposentadoria, assumindo trabalhos parciais e precarizados (Van der HORST et al., 2017).

Já a construção do papel social dos homens no trabalho se faz ao longo de toda a vida, sendo permitido aos meninos acompanharem seus pais fora do lar e se “formarem" nos espaços ditos masculinos (WINDMÖLLER; ZANELLO, 2016).

No mundo ocidental tem sido crescentemente estudada a teoria hegemônica da masculinidade, que incorpora conceitos socialmente construídos e geralmente associados a ser branco, heterossexual, de classe média e possuir comportamentos que denotem assertividade, domínio, controle, força física e controle emocional (EVANS et al., 2011). Como desdobramento dessa teoria, tem-se o dispositivo de eficácia dos homens, construído socialmente por uma virilidade sexual e laborativa, com desempenho eficaz do seu papel de provedor e chefe da família (ZANELLO, 2016).

Outro imperativo associa-se a esses dois papéis e diz respeito à exigência de uma saúde perfeita, para que possam produzir e sustentar a família. Diante desse

1 Esses últimos dados de cargos políticos foram disponibilizados pela publicação em revisão feita em 2018 e são referentes a 20.12.2017 (IBGE, 2016).

Laborare. Ano IV, Número 6, Jan-Jun/2021, pp. 152-171. ISSN 2595-847X. https://revistalaborare.org/ DOI: https://doi.org/10.33637/2595-847x.2021-70 
imperativo, com frequência observa-se a negação do adoecimento, que propicia o atraso ou mesmo impede o diagnóstico de algumas doenças, como, por exemplo, a depressão, uma vez que o homem não pode ser frágil, não pode sentir tristeza e não pode chorar (APESOA-VARANO; BARKER; HINTON, 2015; WINDMÖLLER; ZANELLO, 2016).

\section{TRAJETÓRIA LABORAL E APOSENTADORIA: COMO AS DESIGUALDADES DE GÊNERO CONDICIONAM ESTA RELAÇÃO?}

Cada vez mais, intensifica-se o debate sobre a escolha e as reais possibilidades de se manter, ou não, trabalhando após a aposentadoria. Nessa discussão, existe ainda uma escassez de estudos que abordem o trabalho após a aposentadoria pelo enfoque de gênero. Com frequência os pesquisadores ignoram as desigualdades de gênero na vida laboral e na aposentadoria ou simplesmente optam por tomar apenas a trajetória masculina como referência (LORETTO; VICKERSTAFF, 2015).

Geralmente, a abordagem de gênero relaciona os achados de trabalho após a aposentadoria com a vida ocupacional pregressa, discutindo a trajetória laboral de mulheres e a continuidade das iniquidades entre homens e mulheres na velhice (FINCH, 2014; FELIX, 2016; DINGEMANS; MÖHRING, 2019).

Nesse sentido, observa-se que as mulheres, em países desenvolvidos, estendem mais do que os homens o seu período de trabalho devido às desigualdades do mundo do trabalho, que as desfavorecem na pavimentação da sua aposentadoria e as obrigam a buscar uma complementação de renda.

Assim, as mulheres trabalham mais tempo para compensar baixas fontes financeiras, reflexo de sua vida laborativa caracterizada por trabalho parcial e interrupções para cuidar dos filhos pequenos. Paradoxalmente, embora sejam as que mais precisam estender o trabalho na velhice, são as que têm mais dificuldade de conseguir trabalho, perpetuando-se as desigualdades de gênero (FINCH, 2014; Di GESSA et al., 2017).

É preciso fazer uma referência especial à situação observada entre o funcionalismo público, uma categoria ocupacional que possui regras mais isonômicas, que contemplam os salários e as aposentadorias de homens e mulheres, ressalvando-se que estas últimas podem aposentar-se mais cedo. No serviço público, existem os mesmos mecanismos de seleção e de planos de cargos e salários, o que, em tese, estabeleceria condições iguais para homens e mulheres, no percurso de suas carreiras. Entretanto, mecanismos androcêntricos, muitas vezes, impedem que isso ocorra com

Laborare. Ano IV, Número 6, Jan-Jun/2021, pp. 152-171. ISSN 2595-847X. https://revistalaborare.org/ DOI: https://doi.org/10.33637/2595-847x.2021-70 
delegação de cargos de coordenação e de chefias aos homens. Ainda assim, é provável que muitas mulheres, quando podem, escolham o serviço público na tentativa de sofrer menos efeitos das desigualdades do mundo do trabalho. Ressaltase ainda que no serviço público os direitos à licença maternidade e à amamentação são amplos e claramente garantidos às mulheres (AQUINO, 2009).

Se há adversidades na busca de trabalho na velhice para aquelas mulheres em países chamados desenvolvidos ou de maior renda, as dificuldades enfrentadas pelas idosas no Brasil são bem maiores, com menor oportunidade de trabalho, o que pode expulsálas mais cedo do que os homens do mercado de trabalho formal (FELIX, 2016). Essa vulnerabilidade é maior para as mulheres em toda a sua trajetória profissional, se estendendo para a velhice. $\mathrm{O}$ mesmo autor ressalta que "a regulamentação trabalhista brasileira e as leis de proteção à pessoa idosa também foram incapazes de garantir à mão de obra feminina com mais de 60 anos um nível de participação igualitária nas organizações empresariais" (FELIX, 2016:254).

Não se pode esquecer que muitas mulheres idosas, tanto em países de renda alta quanto nos países de média e baixa renda, acabam se inserindo em trabalhos precarizados, informais, de cuidadoras e domésticos, em sua maioria sem regulamentação, demarcando claramente as desigualdades de gênero (FARRÉ, 1996; KRELING, 2001; FINCH, 2013; LORETTO; VICKERSTAFF, 2015).

Gênero, aspectos psicológicos e socioeconômicos - escolaridade e remuneração na aposentadoria -, estado de saúde, relação prazer/desprazer com o trabalho anterior, tipo de seguro social obtido e a idade estão diretamente envolvidos na decisão ou obrigatoriedade de aposentados em continuarem trabalhando e nas repercussões do trabalho sobre a saúde psíquica e o bem-estar (FINCH, 2014; Di GESSA, 2017).

\section{CUIDADOS INFORMAIS A PARENTES E OPORTUNIDADE DE TRABALHO TARDIO}

$\mathrm{Na}$ "escolha" de continuar trabalhando após a aposentadoria, o conflito trabalho/família constitui-se um ponto central. Como já comentado, a construção social de gênero acompanha as mulheres em todas as fases do ciclo de vida e não poderia ser diferente no envelhecimento e na velhice. Existe uma interrelação entre o tempo de trabalho das mulheres e o tempo gasto nas responsabilidades domésticas, o que significa dizer que as mulheres com maior tempo gasto no domicílio têm, em linhas gerais, maior dificuldade de construir uma carreira no trabalho, que possa ser bem remunerada e traga ganhos simbólicos que sirvam de incentivo e atrativo para a

Laborare. Ano IV, Número 6, Jan-Jun/2021, pp. 152-171. ISSN 2595-847X. https://revistalaborare.org/ DOI: https://doi.org/10.33637/2595-847x.2021-70 
continuação do trabalho após a aposentadoria. Além das dificuldades de inserção no mercado de trabalho, reflexo de uma trajetória laboral atravessada por gênero, há que se levar em consideração o seguinte fenômeno na velhice das mulheres.

Na idade madura ou na velhice, as mulheres já não têm filhos para cuidar, mas cuidam de netos e, especialmente, de pais ou parentes, que necessitam de cuidados contínuos. Estudos têm mostrado a associação entre o maior tempo despendido em cuidados informais a parentes e a inserção em trabalhos precarizados e parciais por mulheres europeias com mais de 50 anos (CICARELLI; VAN SOEST, 2018).

Percebe-se, então, que as mulheres estão frequentemente em desvantagem em relação aos homens, por ser o cuidado considerado socialmente uma atribuição feminina, e, portanto, a ser exercido basicamente por mulheres (NALDINI; PAVOLINI; SOLERA, 2016). Ao se observar homens norte-americanos, que se dedicam a cuidar de parentes, as situações tendem a se igualar pela aposentadoria ser mais precoce e com menor reinserção no mercado de trabalho, desaparecendo as diferenças entre eles (STOIKO; STROUGH, 2018).

\section{TRABALHO DE IDOSOS E IDOSAS: DADOS QUE EVIDENCIAM A PRECARIZAÇÃO}

A possibilidade de estender a vida laboral está diretamente relacionada com a qualidade do envelhecimento, que será vivenciado de acordo com contextos sociais, raciais e de gênero. Para que pessoas idosas trabalhem na velhice é imprescindível que as sociedades considerem esses fatores, além das especificidades de cada país, com seu nível de desenvolvimento e condições socioeconômicas e política (MINAYO; COIMBRA, 2002; NILSSON, 2016).

Estudo desenvolvido por Felix (2016) revela aspectos relevantes do mercado de trabalho para idosos no Brasil. Utilizando dados do PNAD, o autor destaca que, de 1992 a 2012, houve um declínio de $12 \%$ na taxa de atividade de idosos e idosas, apesar do crescimento de idosos na População Economicamente Ativa Idosa estar acima do crescimento da População Economicamente Ativa. A condição do idoso no mercado de trabalho geralmente é a de aposentado, trabalhando por conta própria como autônomo. Os idosos que se mantêm trabalhando após a aposentadoria se submetem a vínculos trabalhistas precários ou são informais, o que aumenta sua vulnerabilidade social (FELIX, 2016).

Laborare. Ano IV, Número 6, Jan-Jun/2021, pp. 152-171. ISSN 2595-847X. https://revistalaborare.org/ DOl: https://doi.org/10.33637/2595-847x.2021-70 
Dados comparativos sobre a presença de mulheres e homens no mercado de trabalho apresentam diferenças importantes entre os que se mantêm trabalhando na velhice. Com base em dados do PNAD, de 2012, Santos e Barbosa (2014) destacam que 62\% dos homens idosos exerciam atividade profissional, enquanto apenas $25 \%$ das idosas o faziam. Menos de $10 \%$ das idosas após os 60 anos empregavam-se em regime de CLT e 30\% trabalhavam por conta própria; com 70 anos ou mais, o trabalho para consumo próprio atingia $45 \%$ do total dos trabalhos, sendo o único tipo de trabalho com ascendência constante na vida das mulheres, a partir dos 15 anos de idade.

Desse modo, é essencial discutir a precariedade dos trabalhos de idosos após a aposentadoria. Para além dos vínculos precários de trabalho na velhice, muitos trabalhadores idosos vivenciam a própria existência como precária, relacionada à preocupação de sustentarem seus empregos a longo prazo, uma vez que muitos são obrigados a trabalhar para aumentar seus ganhos e se deparam com fontes limitadas de renda na aposentadoria. A oferta restrita de empregos e a renda insuficiente após a aposentadoria precisam ser mais bem estudadas para que se encontrem alternativas de suporte social. A situação de precariedade decorre de uma combinação de fatores como o crescimento continuado do fenômeno da precarização do trabalho, desmonte do Estado de Bem Estar Social e da proteção social e baixa renda. Nesse cenário, as mulheres são as mais atingidas pois acumulam menos ao longo de sua trajetória laboral e dispõem de menos recursos financeiros (LAIN et al., 2019).

Neste contexto também se deve questionar a proposta da extensão do tempo de trabalho com aumento da idade para obtenção do benefício da aposentadoria, indagando-se se, ao invés de se estender o tempo de trabalho, os Estados não deveriam levar em consideração os trabalhadores precarizados para estabelecimento desses critérios, notadamente para as mulheres, que são as mais prejudicadas (NILEIME; LORETTO; STREET, 2017).

Na mesma direção, recomenda-se a ampliação da inserção dos trabalhadores idosos no mercado não como uma receita única, e sim, considerando as suas habilidades. Nesse sentido, é recomendado que as políticas de postergação da aposentadoria sejam estabelecidas de acordo com a diversidade entre os trabalhadores (FELIX, 2016).

Recentemente, a sociedade brasileira esteve mergulhada em intenso debate sobre as mudanças na previdência social, cujas reais repercussões sobre a vida dos trabalhadores ainda não são bem conhecidas, mas pode-se esperar que essas novas regras tornem ainda mais precárias as condições de saúde e de vida dos idosos e das idosas do nosso país.

Laborare. Ano IV, Número 6, Jan-Jun/2021, pp. 152-171. ISSN 2595-847X. https://revistalaborare.org/ DOI: https://doi.org/10.33637/2595-847x.2021-70 


\section{TRABALHO APÓS A APOSENTADORIA E SAÚDE}

O papel desempenhado pelo trabalho após a aposentadoria sobre a vida e saúde dos trabalhadores não é consensual. Ainda que alguns estudos apontem para as relações entre trabalho após a aposentadoria e melhor saúde, é importante ressaltar que o benefício da aposentadoria sobre a saúde está intrinsecamente relacionado ao tipo de trabalho desenvolvido anteriormente.

Pessoas que sofrem maior sobrecarga física se beneficiam ao se aposentarem, por decisão de não continuarem trabalhando após a aposentadoria em um trabalho de tamanho desgaste, que nada contribui para a sua saúde. Por outro lado, um trabalho com melhores condições, gratificante e reconhecido, torna-se favorável à saúde, incluindo-se a saúde psíquica (MAZZONA; PERACCHI, 2014).

Outros autores entendem que aqueles que permanecem trabalhando após a aposentadoria comporiam um seleto grupo de idosos saudáveis, o que explicaria melhor saúde do que os que não continuam trabalhando. Ou seja, para quem tem boa saúde e vantagens socioeconômicas, estender o tempo de trabalho para além da pensão é benéfico (Di GESSA et al., 2017).

Entre as manifestações e queixas observadas em trabalhadores aposentados que não voltaram ao mercado de trabalho estão insônia, hipertensão arterial, dores musculares, depressão, sentimento de desvalia e síndrome do pânico, além de outros aspectos como redução do convívio social e dificuldade de administração do tempo em relação aos afazeres cotidianos (HOFFMANN; ZILLE, 2017).

O trabalho após a aposentadoria é um fator de proteção para a saúde de aposentados, especificamente a saúde psíquica, como sintomas depressivos ou até mesmo depressão? Esta é uma questão que aguarda resposta e merece ser mais investigada (DAVE; RASHAD; SPASOJEVIC, 2008).

Um dos fatores extremamente relevantes para a saúde psíquica, no processo da aposentadoria, é o desejo (ou não) de se aposentar, que inclui a expectativa de continuar trabalhando e não se aposentar, assim como o desejo de se aposentar mais precocemente e conseguir fazê-lo (FALBA; GALLO; SINDELAR, 2009).

O que se pode observar dessa discussão é que as condições socioeconômicas, em conjunto com a trajetória de trabalho, com as possibilidades e impossibilidades de ganhos simbólicos, são eixo estruturante da vivência da aposentadoria e dos

Laborare. Ano IV, Número 6, Jan-Jun/2021, pp. 152-171. ISSN 2595-847X. https://revistalaborare.org/ DOl: https://doi.org/10.33637/2595-847x.2021-70 
benefícios angariados nessa fase da vida. Assim, apenas o fato de trabalhar é insuficiente para se propalar que a saúde será beneficiada, justificando-se a prorrogação da aposentadoria. Essa ideia veiculada em alguns países, supostamente, busca atingir objetivos de provável caráter econômico, para além da preservação da saúde dos aposentados (KREKULA, 2017), que, em realidade, precisam se submeter, em sua grande maioria, a trabalhos precarizados.

\section{CONSIDERAÇÕES FINAIS}

A realidade socioeconômica de países de renda alta é diversa da encontrada no Brasil, especificamente no que diz respeito a condições de trabalho, ofertas de emprego, renda e pensões de aposentadoria, ainda que também apresentem situações de precarização do trabalho. Da mesma forma, não se pode deixar de assinalar que a conquista de alguns direitos por mulheres, nos Estados Unidos da América e na Europa, encontra-se em um patamar diferente do encontrado no Brasil.

No nosso país, observa-se a inserção de idosas em trabalhos muito precários, especialmente trabalhos domésticos e de prestação de cuidados a doentes e a pessoas mais velhas, muitas vezes exercidos sem regulamentação e na informalidade. Ou ainda, muitas vezes, há uma antecipação do período de aposentadoria das mulheres para que possam exercer o papel de cuidadoras de pessoas mais idosas de suas famílias, o que interfere nos seus rendimentos.

Com isso, essas mulheres idosas, muitas vezes, renunciam a um trabalho formal e se inserem em trabalhos em que são duplamente vulnerabilizadas: como idosas, em relação às mulheres mais jovens; e como mulheres, em relação aos idosos. $\mathrm{Na}$ literatura internacional, este debate vem sendo feito de forma intensa, tanto na direção de reconhecerem-se alguns trabalhos de idosos como precários, como na direção de reconhecer-se o trabalho das mulheres no cuidado dos filhos, a ser considerado no momento da contagem de tempo para a aposentadoria (VLACHANTONI, 2012). Esse seria um mecanismo de retribuição às mulheres pela maior carga de trabalho ao longo da vida, porém, vale ressaltar que no horizonte encontra-se o objetivo primordial de redistribuição, entre mulheres e homens, de responsabilidades no cuidado da casa e dos filhos.

No Brasil, pode-se discutir de imediato a necessidade de se pensar o momento da aposentadoria e os efeitos sobre a saúde dos/as trabalhadores/as, conforme recomendado por Mazzona e Peracchi (2014), considerando-se o contexto em que se insere o trabalho desenvolvido e suas particularidades de gênero.

Laborare. Ano IV, Número 6, Jan-Jun/2021, pp. 152-171. ISSN 2595-847X. https://revistalaborare.org/ DOl: https://doi.org/10.33637/2595-847x.2021-70 
Da mesma forma, os trabalhos precisam ser pensados como diversos, na oferta de gratificações simbólicas, ou restritos apenas à sobrecarga física e psíquica, quando são debatidos os benefícios e os prejuízos na continuação do trabalho após a aposentadoria. Finalmente, faz-se urgente, no nosso país, a regulamentação de trabalhos informais no sentido de evitar que esses trabalhos se tornem cada vez mais precarizados, tanto para jovens quanto para velhos, sempre fazendo a ressalva de que os idosos acabam pagando um preço maior, devido às dificuldades próprias da idade e aos efeitos mais presentes na saúde. Sinaliza-se, mais uma vez, que as idosas são as que se encontram em situação mais vulnerável e medidas de proteção específicas devem ser pensadas quando se planeja uma política de incentivo ao trabalho após a aposentadoria.

Embora as mudanças nas regras da previdência social já tenham sido implementadas, não findou o debate acerca das relações entre o tempo de trabalho, o trabalho após a aposentadoria e a saúde, do entendimento dos fatores que favorecem ou impedem a busca desse trabalho, da "escolha" ou obrigatoriedade implicadas nesse processo, da precarização do trabalho dos idosos e idosas e do papel dos cuidados familiares na saída precoce do mercado de trabalho por parte das mulheres e no impedimento para o retorno a esse mercado após a aposentadoria.

\section{REFERÊNCIAS BIBLIOGRÁFICAS}

ANTUNES, M. H.; MORÉ, C. L. O. O. Família, trabalho e aposentadoria: uma revisão da produção científica no cenário brasileiro. Contextos Clínicos, v.7, n. 2, p.145-154, 2014. https://doi.org/10.4013/ctc.2014.72.03

APESOA-VARANO, E. C.; BARKER, J. C.; HINTON, L. Shards of sorrow: Older men's accounts of their depression experience. Social Science \& Medicine, v.124, p.1-8, 2015. https://doi.org/10.1016/j.socscimed.2014.10.054

AQUINO, E.M.L. Gênero e ciência no Brasil: contribuições para pensar a ação política na busca da equidade. In: Heilborn, M. L.; Aquino, E.M.L.; Barbosa, R.M.; Bastos, F. I.; Berquó, E.; Rohden, F. (Org.), Sexualidade, reprodução e saúde. 1ed. Rio de Janeiro: Editora FGV, Vol. 1, 2009. p. 57-72.

BITENCOURT, B.M. et al. Para além do tempo do emprego: o sentido do trabalho no processo de aposentadoria. Revista de Ciências da Administração, v.13, n.31, p. 30-57, 2011. https://doi.org/10.5007/2175-8077.2011v13n31p30

BOEHS, S.T.M. Revisão da literatura latino-americana sobre aposentadoria e trabalho: Perspectivas psicológicas. Revista Psicologia: Organizações e Trabalho, v.17, n.1, p.54-61, 2017. https://doi.org/10.17652/rpot/2017.1.11598

Laborare. Ano IV, Número 6, Jan-Jun/2021, pp. 152-171. ISSN 2595-847X. https://revistalaborare.org/ DOl: https://doi.org/10.33637/2595-847x.2021-70 
BRITTO da MOTTA, A. As dimensões de gênero e classe social na análise do envelhecimento. Cadernos Pagu, n.13, p. 191-221, 1999.

CAMARANO, A. A. (Org). Os novos idosos brasileiros: Muito além dos 60? Rio de Janeiro: IPEA, 2004. 596 p. https://www.ipea.gov.br/portal/index.php? option=com_content\&view=article\&id=5476. Acesso em 30.01.21

CASTRO, M.G. \& LAVINAS, L. Do feminino ao gênero: a construção de um objeto. In: COSTA, A.O.; BRUSCHINI, C. (Org.) Uma questão de gênero. Rio de Janeiro: Ed. Rosa dos Tempos, 1992. 336 p.

CICCARELLI, N., VAN SOEST, A. Informal Caregiving, Employment Status and Work Hours of the 50+ Population in Europe. Springer US, 2018. https://doi.org/10.1007/s10645-018-9323-1

DAVE, D., RASHAD, I. SPASOJEVIC, J. The effects of Retirement on Physical and Mental Outcomes. Working paper, v.1, n. 5, Jan.2008. https://doi.org/10.3386/w12123

DEBERT, G. G. Gênero e Envelhecimento. Estudos Feministas, n.1. p.33-51,1994.

DEJOURS, C.; ABDOUCHELI, E.; JAYET, C. Psicodinâmica do Trabalho: contribuições da Escola Dejouriana à análise da relação Prazer, Sofrimento e Trabalho. Tradução de Betiol, M. I. S. et al. São Paulo: Atlas, 1994.

DE MELO, H. P.; THOMÉ, D. Mulheres e poder: histórias, ideias e indicadores. Rio de Janeiro: Editora FGV, 2018.

DI GESSA, G.; CORNA, L.M.; PLATTS.L.G.; WORST, D.; MCDONOUGH, P,; SACKER, A.; PRICE, D.; GLASER, K. Is being in paid work beyond state pension age beneficial for health? Evidence from England using a life-course approach. J Epidemiol Community Health, v.71, n. 5, p. 431-438, 2017. http://dx.doi.org/10.1136/jech-2016-208086

DINGEMANS, E.; HENKENS, K. Involuntary retirement, bridge employment, and satisfaction with life: A longitudinal investigation. Journal of Organizational Behavior, v. 35, n. 45, p. 575-591, 2014. https://doi.org/10.1002/job.1914

DINGEMANS, E.; HENKENS, K.; SOLINGE, H. van. Access to Bridge Employment: Who Finds and Who Does Not Find Work After Retirement? The Gerontologist, v. 56, n.4, p.630-640, 2016. https://doi.org/10.1093/geront/gnu182

DINGEMANS, E.; MÖHRING, K. A life course perspective on working after retirement: What role does the work history play? Advances in Life Course Research, v. 39, p. 23-33, 2019. https://doi.org/10.1016/j.alcr.2019.02.004

Laborare. Ano IV, Número 6, Jan-Jun/2021, pp. 152-171. ISSN 2595-847X. https://revistalaborare.org/ DOI: https://doi.org/10.33637/2595-847x.2021-70 
DUMAIS, L. Impact of participation of women in science on rethink the place of women especially in occupational health. Woman \& Health, v.18, p.11-25, 1992.

EVANS, J.; FRANK, B.; OLIFFE, J.L.; GREGORY, D. Health, Illness, Men and Masculinities (HIMM): a theoretical framework for understanding men and their health. Journal of Men's health, v.8, n.1, p.7-15, March 2011. https://doi.org/10.1016/j.jomh.2010.09.227

FALBA, T. A.; GALLO, W.T.; SINDELAR, J.L. Work expectations, realizations, and Depression in Older Workers. J Ment Health Policy Econ., v.12, n.4, p. 175-186, 2009. https://www.ncbi.nlm.nih.gov/pmc/articles/PMC3434685/pdf/nihms201658.pdf

FARRÉ, A. F. Prólogo a la edición española. In: ARBER, S.; GINN, J. Relación entre género y envejecimiento. Enfoque sociológico. Madrid: Narcea S.A. de Ediciones, 1996. p.7-9.

FELIX, J. O Idoso e o Mercado de Trabalho. In: ALCÂNTARA, A.O.; CAMARANO, A.A.; GIACOMIN, K.C. (Orgs). Política nacional do idoso: velhas e novas questões - Rio de Janeiro: Ipea, 2016. p.241-263 http://repositorio.ipea.gov.br/handle/11058/9092. Acesso em 23.11.2020.

FERNANDES, N. G; ZORDAN, M. S. Relações entre Trabalho, Saúde e Aposentadoria da Pessoa Idosa: Uma Abordagem Teórica. Rev. Científica da Faculdade de Balsas, Ano III, n.3, 2012.

FINCH, N. Why are women more likely than men to extend paid work? The impact of work-family life history. Eur J Ageing, v.11, p. 31-39, 2014. https://doi.org/10.1007/s10433-013-0290-8

FRANÇA, L.H.F.P.; MENEZES, G. S.; BENDASSOLLI, P. F.; MACEDO, L. S. S. Aposentar-se ou continuar trabalhando? $O$ que influencia essa decisão? Psicol. cienc. prof., v.33, n.3, p.548-563, 2013. http://dx.doi.org/10.1590/S141498932013000300004 .

GERGEN, K.J. A crítica feminista da ciência e o desafio da Epistemologia Social. In: GERGEN, M.McC.(Org.). $\mathrm{O}$ pensamento feminista $\mathrm{e}$ a estrutura do conhecimento. Brasília: Edunb, 1993. p.48-69.

HIRATA, H. O Conceito de trabalho. In: EMILIO, M. et al (orgs). Trabalho e cidadania Ativa para as Mulheres: Desafios para as Políticas Públicas. Prefeitura Municipal de São Paulo-Coordenadoria Especial da Mulher. São Paulo: Casa de Edição, 2003, p 65-69.

Laborare. Ano IV, Número 6, Jan-Jun/2021, pp. 152-171. ISSN 2595-847X. https://revistalaborare.org/ DOI: https://doi.org/10.33637/2595-847x.2021-70 
HOFFMANN, C.D.; ZILLE, L.P. Centralidade do Trabalho, Aposentadoria e seus desdobramentos biopsicossociais. REUNA, v.22, n.1, p.83-102, 2017. https://doi.org/10.21714/2179-8834/2017v22n1p83-102

IBGE. Estatísticas de Gênero - Indicadores sociais das mulheres no Brasil. Estudos e Pesquisas. Informação Demográfica e Socioeconômica, n.38. 2016. https://biblioteca.ibge.gov.br/visualizacao/livros/liv101551_informativo.pdf Acesso em 02.12.2020.

KERGOAT, D. Em defesa de uma sociologia das relações sociais. Da análise crítica das categorias dominantes à elaboração de uma nova conceituação. In: KARTCHEVSKY-BULPORT, A. et al (Org). O sexo do trabalho. Rio de Janeiro: Paz e Terra, 1987. p.79-94.

KREKULA, C.; VICKERSTAFF, S. From Homogenization of Older Workers To Gendered Power Relations and Governmental Precarization. Innov Aging, Jul; 1(Suppl 1), p.1069, 2017. https://doi.org/10.1093/geroni/igx004.3914

KRELING, N. H. Gênero e trabalho na terceira idade. Mulher e Trabalho, v. 1, 2001.

LAIN, D.; AIREY, L.; LORETTO, W.; VICKERSTAFF, S. Understanding Older Worker Precarity: The Intersecting Domains of Jobs, Households and the Welfare State. Ageing \& Society, v. 39, n.10, p. 2219-41, 2019. https://doi.org/10.1017/S0144686X18001253

LORETTO, W.; VICKERSTAFF, S. Gender, age and flexible working in later life. Work, Employment and Society, v.29, n.2, 2015. https://doi.org/10.1177/0950017014545267

MAZZONNA, F.; PERACCHI, F. Unhealthy retirement? Evidence of occupation heterogeneity. IdEP Economic Papers, n.1, 2014. Center for Economic and Political Research on Aging (CEPRA). https://core.ac.uk/download/pdf/20662668.pdf.

MINAYO, M.C.S.; COIMBRA Jr., C.E.A.(Orgs). Antropologia, saúde e envelhecimento. Rio de Janeiro: Editora FIOCRUZ, 2002. https://doi.org/10.7476/9788575413043

NALDINI, M.; PAVOLINI, E.; SOLERA, C. Female employment and elderly care: the role of care policies and culture in 21 European countries. Work, $\begin{array}{llll}\text { Employment } \quad \text { and } & \text { Society, } 30, & \text { n.4, }\end{array}$ https://doi.org/10.1177/0950017015625602 
NASH, J. A decade of research on women in Latin America. In: NASH, J.; SAFA, H. (coord.) Women and change in Latin America. Philadelphia: Bergin \& Carvey, 1985. p.3-21.

NILEIME, A.; LORETTO, W.; STREET, D.A. Gender, Precarious Employment, and Longer Working Lives. In The U.S., Uk, and Ireland. Innov Aging, Jul; 1(Suppl 1), p.1069-1070, 2017. https://doi.org/10.1093/geroni/igx004.3914

NILSSON, K. Conceptualisation of ageing in relation to factors of importance for extending working life - a review. Scandinavian Journal of Public Health, v. 44, p. 490-505, 2016. https://doi.org/10.1177/1403494816636265

RIBEIRO, G.G. et al. Perspectivas sobre a aposentadoria e o trabalho na pósaposentadoria na terceira idade: Revisão da literatura brasileira entre 1994 e 2014. XIV SEPA-Seminário Estudantil de Produção Acadêmica, UNIFACS, 2015. https://core.ac.uk/download/pdf/234554847.pdf. Acesso em 19.01.21.

SANTOS, C. F.; BARBOSA, E. D. O idoso brasileiro no mercado de trabalho e na previdência social: uma análise de 1992 a 2012. Boletim de Informações Fipe, São Paulo, n. 405, p. 22-37, jun. 2014. https://downloads.fipe.org.br/publicacoes/bif/2014/6_bif405a.pdf. Acesso em 28.11.2020.

SCARBOROUGH, W. J.; RISMAN, B. J. Gender Studies. Companion to Women's and Gender Studies, Nova Jersey: John Wiley \& Sons, 2020. p.41-68.

SCHIEBINGER, L. O feminismo mudou a ciência? Bauru: Edusc, 2001.

SCOTT, J. Gênero: uma categoria útil de análise histórica. Educação \& Realidade, v.20, n. 2, p.71-99, 1995.

STAUDINGER, U. M., FINKELSTEIN, R., CALVO, E., \& SIVARAMAKRISHNAN, K. A global view on the effects of work on health in later life. The Gerontologist, v. 56 (Suppl. 2), p. S281-S292, 2016. https://doi.org/10.1093/geront/gnw032

STOIKO, R. R., STROUGH, J. His and her retirement: Effects of gender and familial caregiving profiles on retirement timing. The International Journal of Aging and Human Development, v. 89, n. 2, p. 131-150, 2019. https://doi.org/10.1177/0091415018780009

STREET, D.A.; Ni LEIME, A. Extending Women's Working Lives...All The Way To The Precariat? Innov Aging, Jul; 1(Suppl 1), p.1069, 2017. https://doi.org/10.1093/geroni/igx004.3914 
VAN DER HORST, M.; LAIN, D.; VICKERSTAFF, S.; CLARK, C; GEIGER, B.B. Gender roles and employment pathways of older women and men in England. SAGE Open, 2017. https://doi.org/10.1177/2158244017742690

VLACHANTONI, A. Financial inequality and gender in old people. Maturitas, v.72, n.2, p.104-107, 2012. https://doi.org/10.1016/j.maturitas.2012.02.015

WHARTON, A. S. The sociology of gender: An introduction to theory and research. Nova Jersey: John Wiley \& Sons, 2009. 279.p.

WINDMÖLLER, N.; ZANELLO, V. Depressão e masculinidades: uma revisão sistemática da literatura em periódicos brasileiros. Psicologia em estudo, v.21, $\mathrm{n}$. 3, p. 437-449, jul-set 2016. https://doi.org/10.4025/psicolestud.v21i3.31896

ZANELLO, V. Saúde Mental, Gênero e Dispositivos. In: DIMENSTEIN, M. et al (Orgs). Condições de vida e saúde mental em contextos rurais. São Paulo: Intermeios, 2016. p.223-245.

Recebido: 08/12/2020

Revisado: 08/01/2021

Aprovado: 05/02/2021 